\title{
Paradoxes of Welfare: Universality, Truth, and Power in Modern Welfare Provision
}

\author{
Kaspar Villadsen \\ Copenhagen Business School, \\ Denmark
}

\section{Introduction}

This Chapter explores paradoxes in modern welfare provision. In so doing, it both engages with theoretical expositions of the contradictions within modern forms of governing and by presenting three specific case studies on paradoxical welfare. The chapter draws in particular upon insights from Michel Foucault and governmentality writers, and empirically it uses studies from Denmark done by the author and one done by a fellow researcher. First the chapter presents the view on governmentality as it was developed by Foucault and writers who draw on his framework for understanding modern power. This section especially highlights the paradoxes inherent in modern ways of governing, and it discusses how these paradoxes re-emerge and give shape to modern welfare provision. Next, the chapter explores three cases of concrete welfare provision with a focus on its inherent paradoxes. The first case is on the preparatory training of unemployed people, the second concerns anti-authoritarian dialogue techniques used in motivational therapy, and the third examines health promotion by means of 'playful' techniques purporting to influence individuals' identity-work. Finally, a brief discussion is offered on how paradoxes may be handled not only analytically but also by practitioners. The point of departure of the chapter is that paradoxes constitute a persisting and integral property of modern welfare provision. This means that we may hardly hope to suspend or resolve them once and for all, but should rather look for ways of rendering them productive.

\section{Governmentality: A prism for observing paradoxes}

In the tradition of critical analyses of power offered by Foucault and his interlocutors, particular attention is paid to paradoxes inherent in modern exercises of power. As an immediate marker, we may say that the perspective examines the problem of 'governing freedom'. More precisely this problem concerns how in modern societies authorities may govern formally free individuals, and at the level of politics, how state authorities may regulate when confronted by a civil society characterised by a fundamental capacity of selfregulation. These broad, diagnostic observations rely upon the approach to liberalism taken by Foucault and more recent 'governmentality studies' (Barry et al., Rose 1993; Dean 1999). Liberal government, on this view, has an internal self-problematizing impetus which makes 
it sceptical towards (state) planning, in-depth regulation and control of human affairs, while it nevertheless intervenes to ensure the play of 'natural' regulation within the economy or civil society. This double gaze, which observes its objects as at the same time natural and cultivated, gives to liberalism (in its different forms) a "prodigiously fertile problematic" inciting critique of existing forms of governing and the invention of new ones (Gordon 1991: 18). On this account, then, the key paradox in liberal welfare states is, in brief, their impetus to govern that which is fundamentally, and by its nature, self-governing.

Another key paradox is the concomitant historical emergence of a double-sided citizenfigure in modern welfare states. That is, the citizen appears concomitantly as a formal, juridical category, whose autonomy should be respected and a as a living being that needs discipline, training, care, empowerment and whose health and risks should be looked after. An admittedly oversimplified reading of Foucault's historical work suggests that the establishment of modern welfare states based on rights and the delineation of the state's proper scope of intervention was, paradoxically, accompanied by a multiplication of institutions and expertise indeed concerned with detailed interventions into the lives of citizens. The curious co-existence within modern welfare states of a discourse of formal rights and a proliferation of detailed technologies aimed at shaping the subjectivity of citizens is noted several places in Foucault's work (Foucault, 1982; 1994). Thus, in the famous text The Subject and Power, Foucault argues - contrary to certain prevalent theories - that the modern state is not at all indifferent to the individualities of its population, quite the opposite:

Most of the time, the state is envisioned as a kind of political power which ignores individuals, looking only at the interests of the totality or, should I say, a class or a group among the citizens. That's quite true. But I would like to underline the fact that the state's power (and that is one of the reasons for its strength) is both an individualizing and a totalizing form of power. (Foucault, 1982: 213).

Foucault explains further that a key reason why the modern state makes use of such an individualizing strategy is that it has integrated several components of pastoral power, i.e. the rationality and form of governing characteristic for ecclesiastical institutions. One crucial characteristic is that this pastoral power is "coexstensive and continuous with life; It is linked with a production of truth - the truth of the individual himself'. (Foucault, 1982: 214). As a consequence of this integration, the exercise of political sovereignty became infused with a pastoral rationality concerned with securing the prosperity and happiness of all and each. It is clear that this individualizing power, in terms of its dependence of knowledge of individuals' views, values, and identities, stands in immediate contrast to a formal-legal, universalizing conception of the citizen. Foucault offers, then, by drawing this genealogical trajectory an alternative understanding of the paradox of universality, still pertinent to so many areas of concrete welfare provision.

A related way of describing the paradoxical character of welfare provision is to emphasize the self-contradictory nature of liberalism, understood as a rationality fundamental for modern welfare states (irrespectively of specific party political governments). Liberalism is self-contradictory since it requires already autonomous individuals while at the same time it develops programs to foster and shape independence (Hindess, 1993). This paradox becomes more intense and delicate if we consider that liberal thinkers and practitioners for the most part already recognise that measures to bind individuals contractually and morally to the social order is both a hindrance and precondition of freedom. 
We must take care, however, not to insert the problem of welfare paradoxes within a register of ideology critique. It would be tempting to see the real expansion of disciplinary welfare apparatuses as happening under the guise of a background music singing the song about a minimal state. Yet, as has already been indicated in the above, Foucault and more recent writers on governmentality urge us to see liberalism not as an abstract doctrine which is never accomplished or might be severely contradicted by real-life liberal arrangements. Liberal forms of governing rather tend towards offering recurrent critique of existing governmental arrangements, including those that are established through their own procedures and practices. One might say, then, that liberal forms of governing have a certain 'preparedness' for what might happen when governing-how the objects of government react when being governed, how populations and economies are effected, and of course, which forms of resistance and critique that may be provoked in the governed subjects. And so, while liberal governing certainly has certain propensities and predilections, it is a highly flexible machine that holds no dream of a total effectuation of a pre-given set of doctrines. It is rather propelled by another dream, which is how to model the art of government upon the very rationality of the governed themselves: "This, it seems to me, is what characterizes liberal rationality: how to model government, the art of government, how to found the principle of the rationalization of the art of government on the rational behaviour of those who are governed." (Foucault, 2008: 312).

Although this key paradox of how to govern freedom has received great attention within the governmentality literature (Gordon, 1991; Valverde, 1996; Rose, 1999; Dean, 1999), other paradoxes relevant for analysis of welfare provision may be discerned in Foucault's writings. We shall not examine these paradoxes in greater detail here, but may merely mention that another key term in Foucault's work, 'discipline', is fundamentally paradoxical (Foucault, 1995). Discipline is, for Foucault, one the one hand, a set of practical arrangements for normalizing criminals, improving factory discipline, standardizing hospitals, and more. On the other hand, discipline also denotes a 'strategic logic' or an abstract rationale that takes diverse concrete instantiations depending on each particular institutional setting (Villadsen, 2008a: 179). The strategic logic of discipline may be termed a paradoxical one. First, it echoes the paradox of governing freedom: The exercise of discipline in its many variants is at the same time a form of subjugation and precondition for the subject's exercise of power, or 'agency', as sociologists would have it. Discipline may thus be evaluated as having both empowering and constraining effects on the subject. Second, the specific scheme of observation inherent to discipline has a self-propelling, limitless mechanism. Such a view could be substantiated be the simple fact that the normal solution to disciplinary failures is the exercise of more discipline, and so, disciplinary institutions thrive on their failures.

Discipline has, however, also a more formal quality that drives it toward self-perpetuation: Its binary scheme of observation, i.e. normality/deviance, has an unlimited applicability and a stable fixation of each side of the binary is fundamentally unachievable. Since the logic of discipline is relational, an object which is observed as 'normal' in relation to the deviant may subsequently be observed as deviant in relation to another standard of normality. Or put more simply, the disciplinary gaze may observe a population (prisoners, school teachers, job seekers), establish a certain norm of normality and then categorise some individuals as deviant. The population of 'normal' individuals may, however, be observed anew, and some members may again be separated out as deviating sufficiently from the 
norm to be 'abnormal'. One paradox inherent to discipline, then, is that an individual may be at the same time normal and deviant, depending on the context, the norm, the moment and the characteristics of other individuals present. The phrase 'we live in a normalizing society' indicates this relational mechanism in discipline.

Writers in the Foucaultian tradition do not normally theorize the concept of paradox (if they use it at all), when addressing governmental contradictions. Yet, the above framing of governmental ambiguities and contradictions as paradoxes hopefully indicates analytical potentials in using the term. Foucault did never himself theorize the term, but he occasionally uses paradox to describe contradictions inherent in particular forms of government. For instance, he uses the term in his description of the science of police, a rationality of government that emerged in Germany during the $17^{\text {th }}$ and $18^{\text {th }}$ century and had as its goal to maximize the strength of the state by undertaking in depth regulation of social relations. Foucault comments that 'the central paradox of police', is that its objective of governing is "to develop those elements of individual lives in such a way that their development also fosters the strength of the state" (1994: 322). For Foucault, this double objective constitutes a key element in modern forms of government. It always observes the citizen as both a part of the totality of the population and as an individual whose particular welfare must be secured.

We note that Foucault on this occasion (as well as on others) uses a conventional understanding of paradoxes. Here, paradox means a situation which seems to have no logically viable solution, since characterised by the presence of two irreconcilable demands. In such a commonly accepted understanding "paradox may mean a state in which two diametrically opposing ideas/forces are simultaneously present, neither of which can ever be resolved or eliminated" (Stacey, 2003: 11). A bit of analytical complexity could be added to this understanding by drawing briefly (and loosely) upon some basic ideas concerning paradoxes in Niklas Luhmann. This is not the place to debate the compatibilities and incompatibilities between Foucault and Luhmann's systems theory at the level of epistemology (see for instance, Borch, 2005), nor to contrast Luhmann's sympathetic attitude to the modern, rational bureaucracy with postmodern values of fluidity, fragmentation and respect for unique individuality (Villadsen, 2011a; DuGay, 2000). I merely wish to add to my analytical approach a few elementary points from Luhmann which seem immediately reconcilable with Foucault's approach to government and power (Pottage, 1998).

Contrary to most social science, paradoxes are for Luhmann not to be avoided and eliminated. They are rather a basic condition of communication and function as impetus for new communication, and here communication should be understood in a very broad sense encompassing both the use of language, acts, and symbols. Paradoxes rests on the existence of a difference, a distinction with two sides between which there is a certain indeterminacy (Kneer \& Nassehi, 2000). As soon as an observer indicates one side of the distinction, he will be referred to the other side. For instance, to observe what is lawful one immediately needs to indicate the unlawful. The paradox is that this observer (of first order) cannot not observe the distinction upon which his observations rests, and thus he cannot question if the basic distinction of law that distinguishes between right and not-right is in itself rightful. Or, to return to the case of discipline, the paradox is here that the positively indicated side in the distinction normal/deviant is divided again, when we observe that within the 'normals' still some individuals deviate from the norm. The example illustrates that there is nothing 
fundamental about paradoxes; they are rather the property of the communicative operations of social systems.

For systems to reproduce themselves communicatively, they need to put aside the paradox by making it immediately invisible through strategies of 'de-paradoxification'. New distinctions, concepts or programs are needed to recodify or reformulate the paradox so that it becomes manageable; or, so that the complexity of indeterminacy becomes determinable (Luhmann, 1991). The Luhmannian observer (of second order) can observe the communicative strategies that are performed by first order observers to negotiate, reconfigure and displace paradoxes in order to make them less disruptive. Governmentality analysts undertake a similar job, since they also analyze how governmental programs and technologies revolve around particular paradoxes, which they are forced to unfold, negotiate and reformulate to make them less disruptive. The below case examples will be guided by insights from the governmentality literature, supplemented by these basic points about paradoxes offered by Luhmann.

\section{Key paradoxes in welfare provision}

Keeping in mind the insights from Foucault, some of his recent interlocutors, and Luhmann, I will use the term 'governmental paradoxes' to pinpoint challenges and contradictions faced by welfare services broadly. In more specific terms, the paradox of welfare provision will be examined in three different prototypes, that is, 'the paradox of universality', 'the paradox of truth', and 'the paradox of power'. First, with respect to universality, welfare provision generally observes the citizen as at the same time particular and universal. This paradox leads to a series of programs, techniques and institutions that seek to meet the citizen in an open, singular, unrestricted fashion, but nevertheless make reference to some inherent, generalised qualities allegedly resting within each individual. A study below addresses this key problem in social work by exploring a strictly related paradox, that is, the concomitant emphasis on respect of the client's autonomy and a desire to change the personality of clients. Most avenues of social policy and social work emphasize that the client is autonomous, that choices must originate from the client himself, that 'over-selling' services is counterproductive, etc. At the same time, however, social work construes a series of specific aspects of the client as objective problems that demand treatment, elimination or keeping in check (Villadsen, 2004; 2007).

In a short text on the historical emergence of 'the form of knowledge of social work', Mark Philp (1979) expounds key paradoxes in this knowledge-although he does not theorize the term. Philp argues that the knowledge of modern social work is paradoxical since it constructs clients as equipped with a subjectivity which is at the same time universal and particular: "The social worker creates a subject who is characterised by a universal subjectivity, one which applies to all individuals and yet no one in particular" (Philp, 1979: 91; Quoted in Villadsen, 2008a). For this construction, social work draws upon disciplines within the human sciences such as psychology, psychoanalysis, and phenomenology, but Philp argues that social work is irreducible to these disciplines. It has its own regime of truth that revolves around the paradox of how to produce objective knowledge of subjectivity. The key strategy of 'deparadoxification' taken up by modern social workers is, as it is implicit in Philp's analysis, to allude to a not immediately visible subjectivity within the client when representing the client to society or institutional figures such as the judge, the 
doctor, or the parents (Philp, 1979: 99). The image of a miserable and morally decayed pauper who nevertheless possesses an inner humanity and socializable potential, which may be excavated behind his immediate appearance, was created by the philanthropist and passed on to the modern welfare expert (Villadsen, 2011b). This paradox of universality is inherent to welfare institutions which encourage their professionals to meet the specific citizen/user as a 'unique person', and yet need to structure this meeting by standardized categories essential to the universal welfare state (Højlund, 2009). At the practical, institutional level, then, the paradox becomes one of how management may increase the responsiveness toward the particular needs of citizens as users while maintaining the lawbased procedures that safeguard the same citizen's formal rights.

The second paradox is the paradox truth. This paradox has recently been reflected in the emergence of new demands upon professionals to not act as 'besser wissers' or as if they were in possession of the ultimate truths about needs, welfare, health values etc. This paradox of truth has resulted in multifarious technologies that aim a facilitating the production of individual opinions on such matters from clients, patients or other services users. The paradox in this anti-authoritarian kind of truth production is that the professionals may always doubt whether the statements really come from the interior of an autonomous subject, or whether this speech is infected by external forces such as subculture, 'clientization', or addiction (Karlsen \& Villadsen, 2008). The idea of social clients who are divided within themselves between, for instance, authentic willpower and dependency, stems from this paradox.

Foucault suggested an analysis of the historical foundations for the paradox of truth over some famous passages towards the end of The Order of Things (1994, 303-343). There, he argues that the modern episteme - that is, the overriding and fundamental conditions for the production of knowledge in modernity - is marked by an ambiguous figure of Man, paradigmatically visible in Kant's oeuvre. In short, Foucault argues that since the end of the $18^{\text {th }}$ century modern man's framework of perception has been governed by an 'anthropological double structure' which conceives of man as an 'enslaved sovereign' who is at one and the same time free to determine how he lives, works and speaks and determined by his biology, labour and language. This double- and indeed a paradoxical-structure institutes a relentless 'hermeneutics of suspicion' which permeates modern Man's relation to his own production of knowledge of the world as well as of himself. Suspicious of his own status as both knowing subject and knowable object, he questions whether his knowledge succeeds in objectively representing the world, or if it is merely a subjective expression of the forces of biology, labour and language which inevitably govern him, as it were, behind his back? The case study of dialogue techniques below describes recent attempt to negotiate exactly the problem of distinguishing statements originating from the interior will of the speakers from those that are produced by structures in the broadest sense of the term.

The third paradox, the paradox of power, encapsulates the concomitant emphasis on deregulation and regulation in modern welfare states. The problem is that the welfare state wishes to facilitate the diversity of civil society, yet the state often resorts to planning in order to secure this diversity. In many cases, social policies conceive of civil society as an unfathomable residual, as well as a concrete collaborator. Paradoxically, for instance, is that when governmental authorities seek to support and revitalize agents in civil society, they at the same time fear that this very support may infect and undermine the particular rationality 
of voluntary and grass roots organization (Villadsen, 2008b; Villadsen, 2009). More formally, the problem is thus that any premeditated attempt to delimit and strengthen the free, autonomous act always runs the risk of undermining this very autonomy. The fundamentally asymmetrical relations of power between state authorities and civil society agents are therefore sought equilibrated, for instance by means of strategies of 'partnerships', 'projectorganisations', or quality standards defined by civil society agents themselves (Andersen, 2008).

Another version of the paradox of power appears in the relation between centralised state authorities and local welfare services when institutions are viewed as at the same time autonomous agents and formally regulated service providers. This paradox becomes manifest in the concomitant stress on centralized regulation, supervision, and enforcement of nationwide standards and calls for increased local autonomy and user-sensitive diversity in welfare provision which have been voiced across European welfare states (Clarke \& Newman, 1997). The paradox of concomitant delegation and centralization is echoed at the institutional level where a key problem is how management may favour trust and floorlevel initiatives at the expense of documentation and control, while still checking such initiatives by documentation and control?

At the level of client-professional interactions, the paradox of power appears in yet other versions. Generally, client-centred work revolves around concepts of 'empowerment', 'facilitation of the client's development', or 'supporting client-autonomy'. To justify the need for empowerment-work, however, requires that the person to be empowered is first categorized as 'powerless'. Here, the welfare expert takes up the role as 'good despot' who can both name someone powerless and prescribe the means and telos of the process of empowerment (Valverde, 1996; Cruikshank, 1999). The justification for exercising this naming and intervening function is makes reference to a defect of the will, lack of selfesteem, or deprived habits on the part of the disempowered. The idea of an interior willpower that could be awoken to take control of such unfortunate forces rests, as Valverde observes, upon a distinction between passion and reason and techniques for differentiating spaces of rule, creating "a spatial division between two psychic spaces" within the governed subject (Valverde, 1996: 369). The paradox of empowering social work and therapy is that the benefactors need to be observed as disempowered and be placed, as it were, in a disempowering position, in order to be empowered. And so, there is a simultaneous empowerment and a disempowerment. The general strategy of deparadoxification is here a spatial differentiation of the psychic texture of the governed subject (Karlsen \& Villadsen, 2008). An objectification of the subject with reference to the subject's self-control is hereby accomplished.

\section{Activation: Awakening the 'wage earner' in each unique person}

Welfare provision is, as mentioned, characterized by its attempts to strike a balance between the demand to respect the autonomy of the individual and the ambitions to subject the very same individual to a process of transformation. One way of striking this balance is to work for a 'clarification' of the client's wishes and needs through different forms of dialogue (which we will examine below). Another, related, strategy is to concentrate the transformation-work upon specific, isolated aspects in the client, for instance, his view of himself or his surroundings, his manner of speaking, or his habits of dressing. Such aspects 
may be isolated and presented as objective problems which impede the client from getting a job, wean out of substances, or, simply, realizing himself. Delineating the intervention around isolated, 'objective' problems pertaining to the individual client seems at immediate glance to meet the demand to respect him as an autonomous and sovereign person. In this way, it can be imagined that a core of individual autonomy is left untouched, which reassures us that the client may still make free and independent choices. Across different kind of social services, the idea of meeting the particular individual is contradicted by a quest for awakening particular general characteristics in the client.

An illustrative case on this strategy of de-paradoxification comes from training of long term unemployed, which was included in an earlier study of the author (Villadsen, 2004). A manual for how to do preparatory training and activation endorsed by the Danish Ministry of Social Affairs takes as its starting point the paradigmatic liberal position that one must never violate client autonomy (Sørensen, 2001). It was not an arbitrary text within Danish social policy. The extensive manual was offered for download at the homepage of Ministry of Social Affairs, and its principles were thus authorized and promoted for application in concrete activation projects. It stresses, on the one hand, that the client should be respected as a fully autonomous subject who may only be influenced indirectly by shaping the conditions around his choices. On the other hand, the text presents various aspects of the client's personality as objects of manipulation and correction. The manual overcomes the paradox of the concomitant emphasis on autonomy and intervention by means of the following moves: First it asserts that the client is autonomous and self-responsible, and that responsibility should never be taken from him. Instead, the social worker should direct his efforts toward 'the conditions' for the client's choice, in order to make some choices more attractive than others. The client should always be able to maintain the experience that it is himself who has wished a particular service or has made a particular choice (Sørensen, 2011: 98). As we shall observe, however, the 'conditions' for the client's choices are not all strictly external to the client's subjectivity; quite the contrary.

The manual gives a lot of specific recommendations as to how preparatory training of unemployed people should be carried out. The book is intended as " $a$ tool for anyone who works with projects, courses, and other services related to activation or rehabilitation unemployed" (Berg Sørensen, 2001: Dust cover). The manual takes as point of departure that social policy is in the middle of a transformation which means that it needs to be accommodated to citizens who make responsible choices on the basis of their own values and possibilities. This situation creates the well-known dilemma which activation projects can not escape negotiating: "On the one hand, society should offer conditions and possibilities that enable the client to become self-reliant; on the other hand, the client must not be deprived of the responsibility for his own life." (Ibid: 69). In this respect, unemployed constitute a particularly great challenge since many of them have been out of work for so many years, that they have been 'clientized' and thus are inclined to leave the responsibility to the social worker. Sørensen cautions that there is a major risk that welfare provision will have negative effects by creating even more dependency and helplessness. For this reason, the social workers should not to be so eager that they end up 'over-selling' the services offered to the clients. "The efforts should never look as if we are 'pulling somebody's leg' or using pressure, which may leave the clients with the impression that it was the social counsellors and not them who thought that they should be prescribed a particular measure." (Ibid: 98). Rather than enforce, agitate or persuade, the social worker should restrict himself to exercise 
an indirect influence upon the clients' actions and choices. It is a matter of informing, counselling, and, to a certain extent, impelling.

We influence what one might call 'the conditions of action' which frame the clients' responsible choices. The clients are and should always be responsible for themselves and the options they take in relation to their situation and their future. The social counsellors can, however, influence the frames within which they make choices by making some choices more favourable than others. (...) Of course, those choices that one should try and stimulate are those that lead the clients to increased self-reliance. (Ibid: 61).

Activation as it quickly turns out, however, is by no means merely about 'influencing the frames' around the clients' choices and leaving the clients themselves untouched. On the contrary, the instruction book highlights a number of personal aspects in the client, such as the client's perception of himself and particular elements in his surroundings: the labour market, the connection between payment and work, his own resources, what are realistic goals for the future, and more. In addition, it focuses on aspects related to behaviour, selfpresentation, and lifestyle: the client's hygiene, clothing, way of speaking, degree of initiative, and overall, immediate appearance.

A key objective is to 're-install a wage earner's mentality' in the activated clients. The fact is that most clients were originally responsible and characterized by a wage earner's mentality which is regarded as quintessentially human. However, many years as passive recipients of benefits have eroded this fundamental attitude. The book asserts that it is a misunderstanding that people should only work if they are motivated to do so and feel that it brings them personal development. This is certainly not the case for many wage earners, who simply work in order to receive a salary. An important component in activation projects is thus to instruct the participants about the fundamental connection between performing good work and receiving payment.

Many clients show signs of this original wage earner-mindset, which, however, has been damaged by a long period of living as a welfare recipient. This living has annulled the mindset which can be very harmful for these clients' capacity for and motivation to become selfsupporting. For exactly this reason, projects which 're-install' this mindset may be a first step on the pathway to self-reliance. (Sørensen, 2001: 84).

Some clients are even said to hold a 'negative wage earner's mentality', and the goal is to substitute it which its direct opposite. This re-instalment work, however, simply constitutes the overall horizon in activation projects. A range of additional tasks are necessary to take on in order to make clients ready for the labour market. Many of these concern how to work on and eliminate a number of inappropriate or 'incorrect' conceptions of the world which some clients entertain. This goes for, for instance, the view that the labour market is stressful, cold, and impersonal. But this problem also concerns some clients' understanding of what it means to be activated. Some clients hold the incorrect view that activation may be compared to slave labour. This is because they see a passive life on welfare benefit as a real, existing possibility for their survival, and by this token they come to view work in activation projects as 'unpaid slave labour'. According to Sørensen, a major task is to explain the clients that passive living on welfare 'is simply not on offer', and that activation is to be viewed as paid work. "In as far as the clients conceive of themselves as paid workers, their self-esteem will increase." (Sørensen, 2001: 62): 
The instruction book also takes another route to objectify client-problems in that it draws a distinction between what is relevant for the labour market and what is private. First, the book represents the private life of the client as irrelevant for the labour market and something that one should not intervene upon. Nevertheless, a number of rather intimate aspects of the clients' personality are turned into objects of examination and corrective intervention. How is this paradox negotiated? A point repeated in the book is that the social worker should abstain from getting involved in problem pertaining to the clients' private life - at least as long as these problems do not clearly hinder the client's preparatory training for the labour market. But this is a difficult demarcation line. Which aspects of the client's personality may be said to influence his possibilities to enter into paid work, and which aspects may be excluded as private, irrelevant problems? Sørensen says that for some clients it may be 'behaviour- and lifestyle-related aspects' that constitute the barrier for entering the labour market. The book mentions "insufficient personal hygiene, inappropriate clothing, lacking politeness, failure to identify oneself with colleagues' or other people's view of the situation, behaviour which unintendedly is perceived as aggressive, inappropriately submissive conduct" (Ibid: 195). The distinction first introduced in the book between labour market relevant aspects and private aspects of the client's life turn out to be highly fluid and hard to uphold and fixate once and for all. Or, more radically, the distinction between the public and the private realm conventionally though to be antecedent to government, is rather created and reconfigured by the deparadoxifying operations of the program.

The final aspect which the book objectifies as a problem for activation work is the client's visual appearance. The client's looks and immediate appearance is clearly emphasized as decisive for his possibilities on the labour market, and it is not viewed as undue intervention to turn this 'surface' into an object of evaluation and correction. Again, the implicit assumption seems to that it is possible to carry out intervention and manipulation of delineated parts of the client-in this case, his visual appearance-without violating him as an autonomous and self-responsible subject. The book gives an example from a project which indeed took a decisive approach to the clients' appearance. There, professional stylists were asked to evaluate every aspect of the clients' looks and bodily comportment, and in several cases they accomplished "dramatic changes which required of the clients quite a lot of habituation and practice." (Ibid: 197). It is concluded that the clients underwent a radical transformation in which their appearance and self-presentation became much more self-assured. Following the headline 'clients under transformation' this project is commemorated as an exemplary activation project:

The project was exemplary with respect to clarifying the clients professionally, training and making them ready for their entry into the labour market. One of the means was professional stylists who helped the clients with all aspects related to their looks and immediate appearance. They took a systematic approach which included discussion and suggestions for choice of clothe, makeup, perfume, and haircut, and similarly, their way of talking with colleagues and customers face-to-face and over the phone was evaluated and discussed. A particular effort was made to make the women appear more smiling and kind. (Ibid: 197).

The view that women should appear smiling and kind certainly contradicts the ideal of taking each particular individual as point of departure, since it invokes stereotypical assumptions about gender and gendered behaviour. Yet, on the contrary, many of the advices given by the stylists to their clients rest on highly generalized views, that is, irrespective of gender, concerning looks and behaviour. 
To sum up, it has been noted that the training project starts from the dictum about respecting the autonomy of the client and yet includes a series of governmental objects, most of which pertain to the personality of the job-seeker. Problems to be worked upon include job-seekers' choices of dress, hair style and make-up; their personal conduct and self-presentation (manner of speaking, gesture, especially the right balance between eagerness and unobtrusiveness); their attitude towards work and receiving benefits; and, not least, their self-perception and self-esteem (i.e. rather than seeing themselves as powerless and option-less, they should see themselves as flexible and resourceful, with opportunities for work and in life in general). In this way, the project illustrates a widely held conception of the client-subject: that it is possible to manipulate specific client attributes without violating the client as an autonomous and self-responsible subject. These observations resonate with other studies of job training and other kinds of transformative social work which 'fragmentize' the universal judicial subject of rights into a series of subjective experiences and obligations which professionals may objectify as problems needing correction (Mik-Meyer, 2006; Villadsen, 2007). In this way, preparatory job training reconfigures the paradox of the co-existence of the universalistic and particularistic client. The logical indeterminacy is overcome by the creation of definite objects of analysis and intervention.

\section{Dialogues: how to regulate 'free' and 'authentic' statements}

This section presents a case study of dialogue techniques that illustrates and unfolds the paradox of truth in welfare provision. The study was done by the author and a fellow researcher (Karlsen \& Villadsen, 2008). It takes its lead from the proliferation of dialogues as a popular governmental instrument, which has been witnessed across a range of welfare services - a development which followed the critique from the 1980s onwards of excessive expert guidance and welfare professionals who supposedly 'steal the problems' from their clients. The study demonstrates that while dialogue techniques demand that welfare professionals should speak less and allow clients to speak more, they nevertheless subtly regulate organisational domains of speech. Dialogue techniques thus vividly display the paradox of producing the truth: they aim to facilitate free, 'authentic' statements (which are true because they are 'free', that is, unaffected by power), but at the same time a number regulatory procedures pre-shape conversational space.

The problematic that incites the quest for dialogue in welfare provision echoes the paradox of truth sketched out by Foucault in The Order of Things. From the perspective of dialogue technology, the client or patient is at the same time conceived as a centre of meaning, a carrier of his own identity, and as fundamentally shaped by 'structures' determining his behaviour and identity. How can the patient both constitute a carrier of individual truth and be deeply embedded in the collectivity of language and culture? Dialogue technology promises to resolve the paradox by separating out those statements that can be ascribed to the interior will-power of the patient and those that allegedly stem from culture, influences, substances, or even the welfare system itself.

The paradox of truth creates a constant doubt as to whether the discourse produced in client-centred work reflects genuine wishes in patients or if they are inflicted by external factors. The fact that this doubt is emerging with in health counselling is particularly noteworthy, since modern medicine has so far enjoyed a self-assured knowledge privilege: 
truth was guaranteed by the expertise of medicine itself, and openness towards other authorities was severely restricted. Recently, however, the health sector has witnessed a proliferation of books and instructional texts that promote various schemes for conversation as a means to help patients who suffer from 'lifestyle-related' illnesses such as drug abuse, alcoholism, obesity, smoking, and gambling. The general objective is to mobilize through verbalization the patients' own understanding of their problem (Clausen, 2005; Mundt et al., 2003; Dalum et al., 2000; Mabeck et al., 1999).The emergence of dialogues 'at equal terms' within health care challenges the traditional knowledge privilege of medicine and generates a greater complexity of alternative knowledge claims. Or, we might say that the paradox of truth becomes more intense and urgent.

After having emphasised the reconfiguration of speaking positions by which the health professionals are urged to restrain their own expert-discourse and allow patients to speak, Karlsen and Villadsen immediately notes that what the new dialogue technologies call for is not an absolute, but rather a strategic silence:

The one who used to speak must learn to administer speech economically and strategically, in such a manner that he or she by means of silence urges the previously silenced to speak, and through this taciturn administration ties the speaking to his or her words. (Karlsen and Villadsen, 2008: 347)

Most textbooks and professional instruction manuals for health counselling emphasize that any effective treatment of lifestyle-related illnesses must place the patient's own perception of his situation centre stage by listening to his own words. In the textbook Make your patient change lifestyle, it thus says: "Only by listening to the patient is it possible to form an image of the patient's concerns and reflections regarding his or her current behaviour" (Nielsen, 1998: 739). But a key challenge is how to structure the patients' statements in a manner that direct their speech in certain directions and prevent it from going astray and venture into areas that are unrelated to their lifestyle illnesses.

Karlsen and Villadsen give several examples of specific dialogue techniques applied in contemporary health counselling, but here we shall focus on only one of them termed 'the balanced decision scheme' (Botelho, 2002). This tool is particularly well suited to materialize the patient's own 'self-motivating' statements. In practical terms, the balanced decision scheme is designed as a box which consists of four empty squares. The process begins when the patient fills out these squares, either in the presence of a professional or as a 'home assignment'. The fields are marked with the following headlines: 'advantages from continuing' (1); 'disadvantages from continuing' (2); 'disadvantages from quitting' (3) and, 'advantages from continuing' (4).

The squares 1 and 4 makes it possible to register the patient's own stated reasons for change, and in this way, they constitute a reservoir of 'self motivating statements', which the professional can mobilize. (Model 1)

What is figuratively created in this scheme is a divided subject, or better, a subject which is divided inside himself. In this regard, this dialogue technology parallels many other technologies for client-centred work which similarly operates with a subject harbouring an internal division between two psychic spaces, variously termed will-power and dependency, reason and passion, autonomy and dependency, and more. Of course, this posited internal division makes it possible for the health counsellor to address an imagined latent faculty inside patients who fail to comply with treatments. 


\begin{tabular}{|l|l|}
\hline $\begin{array}{l}\text { Advantages from } \\
\text { continuing... }\end{array}$ & $\begin{array}{l}\text { Disadvantages from } \\
\text { continuing... }\end{array}$ \\
\hline & \\
\hline $\begin{array}{l}\text { Disadvantages } \\
\text { from quitting... }\end{array}$ & $\begin{array}{l}\text { Advantages from } \\
\text { quitting... }\end{array}$ \\
\hline & \\
\hline
\end{tabular}

Source: Mabeck et al., 1999

Model 1.

But this construction of a divided subject brought about through the balanced decision scheme has an additional, and, as it were, more directly strategic function. The balanced decision scheme is a tool that not only makes the professional capable of averting, but even of positively utilizing, one of the most fundamental conflicts in traditional health counselling. This is the 'duel' of arguments and counter-arguments for lifestyle changed exchanged between patient and health care professional; a duel that almost always results in polarization and a pacification of the client (Nielsen, 1998: 737).

Within health counselling is has long been acknowledged that the advice of the health counsellor, in particular in the shape of prohibitions, runs the risk of being, not just ineffective, but downright aggravating for the behaviour it intended to correct. A further problem with this unfortunate mechanism is that it undermines not only the credibility of the advice, but also the advisor's authority. Instead of achieving a recognition in the client of the need to change his lifestyle, a social conflict is set in motion involving great risks for the health counsellor to lose his possibilities for influencing the patient. However, the balanced decision scheme offers a solution to this problem by its attempt to internalise the conflict. The immediate conflict between the counsellor and his prohibiting advices and the reluctance of the patience is turned inwards, and is thereby recoded as a conflict resting in the patient's selfrelation. The publication Speaking about change by the national Danish committee on smokingrelated illnesses sates this vividly: "It is a crucial point in motivational interviewing that part of the art of health counselling is to move the discussion of pros and cons of a given lifestyle 'inside' the person you are counselling" (Dalum et al., 2000: 67).

By the use of juxtapositions of pros and cons for undertaking lifestyle changes, the balanced decision scheme materializes the conflict as internal, as originating from within the patient's self-relation. Any possible conflicts between the counsellor's advice and his interpretation of the patient's statements, on the one hand, and the patient's reluctance comply, on the other, may be reduced to a mere symptom of the patient's inner ambivalence (Nielsen, 1998: 737). The balanced decision scheme thus displaces the conflict from a social relation to an internal relation between one physic domain and another inside the patient. 
Once a patient begins to recognize this internal conflict, other dialogue techniques may be mobilised to bring him to reconsider his ambivalence, and on this basis choose the form of lifestyle prescribed by health counselling. In such dialogues, there is a paradoxical double sided demand on the patient with respect to his self-relation: It is a matter of confirming the patient's will to acknowledge their own lack of will-power.

Techniques for health counselling also need, however, to address a problem in the health care professional's typical attitude towards the speaking patient. This problem stems from the fact that health professionals have traditionally been rather sceptical with respect to the truth claims in patients' own discourse on diseases. Thus, part of the injunction that health counsellors should 'meet patients on their own terms' is that they acknowledge (and begin to control) their traditional expert-reluctance against patients' subjective opinions. And so, again it becomes clear that to bring out free and authentic statements and to make sure that their truth value is acknowledged takes quite a lot of work, and part of that work is to make the professional listen with less preordained scepticism regarding the status and utility of the layman's words.

The study points at some possible future consequences of the proliferation of dialogue technologies. It shows how the transformation in the discursive space of institutionalized welfare-most forcefully illustrated in the emphasis on more dialogue-does not mean the abolishment of expert guidance, but rather invokes new forms of government and selfgovernment. The 'dialogue on equal terms' does not in itself guarantee statements which dislodged from power. Contrasting themselves to Habermas and his followers, the authors question the view of dialogue as a universal tool for overcoming social conflicts in modern society. Rather, they see it as "a technology of government, which-by employing and combining an array of detailed techniques - seeks to structure the inter-relations and the self-relations of the participants in accordance with specific logics and objectives". (Karlsen \& Villadsen, 2008: 359).

The authors suggest that the proliferation of dialogue technologies is explainable by the fact that it seems capable of solving, or navigating through, a fundamental paradox in modern welfare states. I would add that this paradox is the paradox of truth. The problem is, the authors say, "how to bring the individual to recognize a particular speech as his or her own? How to turn the individual into an author of statements, which are produced, selected and arranged through discursive ordering procedures?" (Karlsen \& Villadsen, 2008: 360). The study demonstrates how much work there is involved in bringing about 'spontaneous, truthful and authentic' speech. They also demonstrate the paradox that the discourse, which demands that patients, clients or employees should be allowed to speak, does not necessarily give these individuals a right to speak. It remains in the hands of the professionals to determine the procedures and develop the instruments of dialogue. The objective is to fill the room with individuals' authentic statements, but the conversational space is already pre-shaped by regulatory procedures.

By way of conclusion, Karlsen and Villadsen suggest the prediction that as long as welfare state provisions are permeated by the paradox of truth, demands for 'liberating' dialogue technologies are likely to intensify. To bring clients and patients to utter self-responsible, self-examining, and self-sanctioning statements, while simultaneously turning them into authorities of those statements, will remain a de-paradoxifying strategy across welfare services. Future studies must describe how new technologies, new concepts and even new 
institutions arise from this dialogical instance of the paradox of truth. The contradictions and disappointments of dialogue techniques will call for the development of new types of professionalism at the expense of existing ones. A significant task for future analysis of manifestations of the paradox of truth in welfare services is, Karlsen and Villadsen suggest, to help welfare professionals and their managers reflect upon the costs and consequences resulting from the reconstruction of professionalism and their space to make dialogue with their clients.

\section{Playful state power: Health promotion through identity-games}

The last case demonstrates the paradox of power by analysing recent campaigns for health promotion in Denmark. In this national context, during the last twenty years, national health plans have displayed a clearly anti-authoritarian and culturally sensitive character. The National Health Plan launched in 1999, thus made significant efforts to distinguish itself from earlier 'individualizing' and 'excessively authoritarian' health promotion strategies. Lars Thorup Larsen (2003: 9) observes that this health plan rejects the tendency to 'blame the victim' and adopts a concept of 'the everyday environment' as the essential object for campaign measures. This form of health campaign tries to avoid targeting the lifestyles of citizens in a direct, negative and individualizing fashion. Instead, it emphasizes the potential of stimulating the surroundings of the individuals in need of change, to become indirect promoters of health. Rather than intervening by means of centralized state regulation, the objective is to engage local municipalities and civil society in the struggle for 'healthier environments'. This network-type governmental strategy is directed at 'the environment' in a very broad sense, as it seeks to mobilize public institutions under the municipalities, schools, local communities, workplaces, and even group dynamics inside companies - hereby transgressing public/private divisions and sector boundaries. In short, it is a campaign that aims to make other agents undertake their own 'micro-campaigns'. The range of problems arising from this aspiration to govern entities which are self-governing reflects well what I described as the paradox of power.

In 2007, the Danish health authorities invented a new board game, Health at Play, in collaboration with the private parents' association Schools and Society. Earlier Danish public health campaigns were allegedly too individualizing and tutelary, and the game presents itself as anti-authoritarian, 'playful', sensitive to citizens' opinions, and transgressing traditional sector boundaries (National Board of Health, 2007). Health at Play is to be played by parents, both alone or with their children, and it can be played at meetings between parents supervised by a school teacher. The instruction manual states that there is no ambition to force everyone live in the same way, and that a modern society should always leave room for diversity.

As Niels Åkerstrøm Andersen has argued, however, the aim of Health at Play' is indeed to shape the lives of families so that their activities conform more closely to governmental health objectives (Andersen 2008). The core of the game is a set of cards with questions about personal attitudes towards health issues that the players can choose to either agree or disagree with. One attitude might be "parents are the most important role models for children" and the participants must then seek to reach a common agreement on this issue. One may certainly question if 'game' is an adequate name for this initiative which offers no principle of scoring points and has no winners and losers (possible except for 'our health'). 
The aim is to settle responsibilities for children's health between parents, school and pupils. But Health at Play uses no sanctions or control measures; it simply seeks to generate debate and reflections, and establish commonly shared value-in short, it is directed at individuals' identity-work.

The game is a tool used by the health authorities to navigate between respecting the autonomy of individual families and promoting intensified health aspirations of governmental authorities. It does so by oscillating between imagined, 'playful' commitments and real, binding commitments. The participants can choose to merely entertain various commitments to a healthier life style, but they may also decide to make the agreements binding and inscribe them into a contract that is supposed to count in real life. By this token, the game suddenly turns into the much more serious and far-reaching 'game' of changing life style. One may thus say that the game represents the playful part of a multi-pronged strategy for health promotion which also consists of traditional information campaigns, efforts to make healthy food available at the canteens public schools, and more.

Health at Play makes use of a noticeably cross-sector approach. The health authorities use the game to make incursions into the schools and the school-parent relation in their attempt to mobilize new agents to promote health objectives. The health authorities thus envision power as spanning across sectors and institutions. They recognize the need to take into consideration and subscribe to practices and strategies already operating within those domains, for instance in the schools. Thus, the health authorities seem to recognize that they cannot themselves meet their aims for health promotion. Or, as Andersen observes, the health authorities acknowledge that there is no place where power may be possessed (2008: 159). The health campaign, that is, displays a particular way of overcoming the paradox of power (how to govern that which is autonomous and self-governing). Indeed, the authorities understand that power cannot be exercised with authority. It cannot be imposed from 'above' or 'from outside' but must be realized indirectly, by the involved agents themselves, engaged in 'playful' and fluid micro-relations. In this way, the game displays some rather advanced reflections on how to exercise power in a modern context. It thus acknowledges that power must be inherent to its object, here conceived as a multiplicity of social forces that will shape and direct the campaign's strategic goals in diverse and undeterminable ways

In thus attempting to channel their efforts through a number of indirect relations, the Danish national health authorities display some symptoms of what Foucault called 'the State phobia' They do not just harbour scepticism towards state power; they engages in a series of sceptical reflections about government agencies that might govern 'too much' and without respect for, or with insufficient knowledge of, the processes and domains of government (Rose \& Miller, 1992). One may say that the health authorities reflect a conception of power that in a sense pursues Foucault's (methodological) injunction to 'cut off the King's head' and clearly emphasizes the decentred micro-physics of power (Foucault, 1980a: 121). Power is conceived of as an attempt to sway others to act by stimulating their identity work, acknowledging that the health authorities do not constitute the source of power and its effects. What is at stake, then, are strategies that depend upon others' strategies that need to be taken into account.

The study observed how Danish national health authorities navigates the paradox of power by conceptualizing power as something that must be exercised by modelling and fine tuning 
itself according to the rationality of individuals and groups. Consequently the normative standards to be achieved cannot be imposed authoritatively from 'above' but are rather coproduced by very the domain to be governed itself. The case demonstrates how the problem of exercising state power is dealt with by invoking new practices of 'anti-authoritative' and 'user-sensitive' health promotion. This observation constitutes an analytical challenge for critical research from a Foucaultian or broader post structural perspective. The kind of antiauthoritarian campaign strategy evident in Health at Play reflects an understanding of knowledge, identity and power a kin to key tenets of 'critical thinking' such as post structural theorizing, critical pedagogy, and even governmentality studies. What hereby begins to emerge is a circular logic between power and critique in which critical thinking is adopted by authorities that may instrumentalize it for producing new strategies of government. By this token, it becomes increasingly difficult to make a clear distinction between who are 'the radical critics' and who are on the side of 'bureaucratic power'. In other words, a perhaps uncomfortable blurring of the hitherto so self-assuring dichotomy between the 'progressive critics' and the 'representatives of bureaucratic state power' is well under way.

To sum up, in negotiating the paradox of power the recent Danish health campaign takes up a rather complex thinking on power and government which evinces parallels to poststructural concepts of power. Firstly, the campaign articulates a conceptualization of power as mobile and reversible series of 'playful' micro-relations. Secondly, it views power as nonsubjective, productive and as non-localizable within traditional sector demarcations (to be inscribed into various 'environments', agents and locales). Thirdly, the campaign acknowledges that citizen groups and professionals are guided by their particular views and values which will shape the effects of playing about health. Consequently the normative standards to be achieved cannot be imposed authoritatively from 'above' but are rather coproduced by very the domain to be governed itself.

\section{The permanence and potentials of governmental paradoxes}

By way of conclusion, I will briefly offer some thoughts on how governmental paradoxes may be handled, analytically as well as practically. It should be clear that the analytical framework adopted here views paradoxes as a permanent and inevitable feature of modern welfare provision, and modern governing more broadly. Instructive is perhaps to point out some possible approaches to governmental paradoxes that runs counter to a Foucaultian/governmentality, and which we need to take account of in terms of their shortcomings as well as their possibilities.

It is straightforward to explain welfare paradoxes as produced by a mismatch and asymmetry between the institution and its object. We may, for instance, imagine cases where welfare institutions and their professionals are guided by a particular 'doxa', i.e. a set of self-evident and partly implicit ideas, which contrasts with how their clients perceive themselves and their problems. It has been described how social workers at projects for job training and rehabilitation maintain a therapeutic doxa which focuses on personal issues and personal development although they are confronted by clients who believe that their essential problem is related to professional qualifications and possibilities at the labour market (Mik-Meyer, 2006). The approach of the researcher is here one of making explicit to the participants that they are caught up within the doxa, and this 'unveiling' may ameliorate 
the state of affairs by illuminating the fundamental contradictions that generate conflicts and resistance. The researcher who takes this approach is typically particularly attentive to the asymmetries between the professionals in welfare institutions vis-á-vis citizens and users with respect to their possibilities for defining welfare values, programs, and methods.

A prominent solution to the problem of closure and self-referential values in welfare services is the practically oriented reform literature termed New Public Management (NPM) which has received great attention in the last two decades (Lane, 2003; Ferlie et al., 1996; Bozeman, 1993). For this reason we will spent some time discussing NPM in terms of its paradoxyfying and deparadoxyfying effects. In NPM, the general approach to public management is one of identification of problems and achievement of solutions through the choice of adequate managerial tools. There is an assumption that it is possible to clarify the explanatory causes for paradoxes, list alternative solutions, make calculations of costs, gains and risks, and, on this basis, choose a specific managerial instrument. However, critics have claimed that New Public Management has an over-optimistic trust in hard line technologybased control of welfare services, and this observation has relevance for our discussion of the management of paradoxes in welfare provision. It is thus interesting that NPMperspective by and large view technologies as tools to carry out managers' objectives, solve problems and overcoming paradoxes. The possibility that technologies might in themselves create new paradoxes or intensify existing ones is rarely considered in this literature. This point was made by Andersen and Thygesen who demonstrated how NPM technologies entail a diversity of antagonistic images of organisations, while paying particular attention to how a technology of goal-steering rendered organisations' relation to their environment highly ambiguous or even 'polyphonic' (Thygesen \& Andersen, 2007).

As outlined earlier, the concept of paradoxes allows us to go beyond the immediately observable lines of conflict and communicated dilemmas to explore which kind of logical paradoxes that are embedded in specific areas of welfare provision. We further recall that paradoxes are created from the drawing of distinctions that constitute logically impossible dualities which communication is forced to unfold, reformulate and displace. The concept thus allows us to explore how services reforms and new managerial strategies for welfare management need to unfold and 'deparadoxify' the paradoxes of welfare, for instance by inventing new concepts that seek to render the paradoxes less urgent and threatening. We shall follow this approach in the following discussion of NPM as a regime for reform of welfare services. Indeed, NPM may be conceived as a series of concepts and techniques for deparadoxification that never accomplish dissolving or an annulment of the paradoxes but rather have as their effect a dislocation of them, sometimes resulting in the emergence of reshaped and intensified versions of the paradoxes. It is thus telling that NPM often stages itself as a tool to overcome and dissolve starkly articulated juxtapositions between universality versus particularism, rule-bound versus flexible, neutrality versus parochial interests, economic efficiency versus welfare professionalism, managers versus employees, compliance versus commitment, and centralised control versus local freedom. The typical approach of NPM is that it is possible to override or even dissolve the oppositions.

NPM has received lots of critique, many of which are based upon the claim that this managerial regime implies an import into welfare organisations of economic and managerial rationalities that are fundamentally foreign to public welfare provision. In its starkest version, the critique has portrayed NPM as a one-dimensional managerialism which 
is unsuited to capture and contribute to the management of public welfare organisations (Osborne, 2006). Proponents of NPM have to some extent themselves provoked this critique, since the most radical advocates have questioned the legitimacy of key elements in democratic regulation of public welfare services, arguing that it imposes unreasonable constraints upon the management of public services (Meier, 1997). Conversely, observers who are sceptical against the adoption of NPM-principles have argued that there is a fundamental tension between the professional ethics of welfare professionals and MPM which is blind to these ethics because of its key tenets, i.e. its emphasis on economic efficiency, the maintenance of performance standards, and the promotion of management as an independent activity.

The debates about the benefits and the problems of NPM invoke the paradox of universality, but this time predominantly in terms of the more specific problem of how welfare services can be at one and same time guided by particular professional values and by universal standards. This paradox is further intensified by the emergence of NPM as it attempts to give 'management' the status of an autonomous professional rationality put one the same footing as the other significant professional logics of modern welfare provision: medicine, pedagogy, and psychology. One influential tenet of NPM (and managerialism more broadly) is the demand that 'managers must be given the right to manage', as observed by Pollitt (1993: 3). This is the idea that managers cannot perform effective management unless they are granted reasonable room for manoeuvre. From this follows the assertion that also public sector managers must enjoy the freedom to decide over the use of organisational resources in order to maximise desired performances. But this 'liberated manager' of welfare production constitutes a paradoxical figure: He is envisioned as a 'neutral' promoter of a particular managerial rationality! The paradox is produced by a peculiar rewinding of the classic distinction between management and administration (Clarke \& Newman, 1995: 64). The manager was seen as an active decision maker, whereas the administrator merely implemented decisions made elsewhere in an impartial fashion. However, NPM now attributes 'impartial implementation' to the manager's side of the distinction turning it paradoxical. What emerges is the welfare manager 'who needs managerial freedom to implement others' decisions'.

Let us become a bit more specific about this paradoxical welfare manager. One the one hand, he represent a particular managerial rationality which revolves around the goal of achieving increased productivity. Key measures are the setting of performance targets, the instalment of tighter financial control and the creation of more transparency and greater comparability with respect to achievements. On the other hand, the manager is envisioned as a 'neutral' agent who will simply assist welfare organisations in achieving their particular goals which are rooted in particular professional values. Here, the image of the welfare manager is one of an administrative 'relay' or a 'catalyst' who use purportedly neutral technologies of optimization. By this I mean that the figure of the neutral manager entails a view of technologies as tools that may realize or unleash 'latent resources' without influencing or fundamentally shaping the content of welfare services in the process. The paradox of the liberated manager is, in brief, that he figures as at the same time an agent of a new, managerial freedom and as a neutral, administrative relay.

The paradox of the concomitant valuation of the universal and the particular reappears, however, in yet another version under NPM. Here, we start by observing that NPM is often 
promoted as a tool for reforming public services by reference to its capacity to overcome lines of conflicts among employees or irreconcilable orientations towards specific professional values. The basic assumption is that effective achievement of organisational goals depends upon the creation of a 'strong culture' or 'corporate identity' in welfare organisations (Clarke \& Newman, 1997: 62-63). Interesting for present purposes is that NPM to some extent was promoted as a tool to overcome the tensions between concomitant attachments and loyalties of welfare professionals. These competing attachments would include attachment to a particular occupational group and its professionalism, attachment to the local, employing organisation, and even attachment to unarticulated notions of 'public service' in general (Clarke \& Newman, 62). Strategies to built strong corporate culture and commitment to the mission of the organisation would conceive of such extra-organisational loyalties as problems that needed to be addressed by management.

The new managerialism placed great stress on giving up of traditional modes of attachment and sought to bridge the motivation gap by combining culture management (the creation of purpose and meanings) with performance management (measuring what really matters). It stresses reduced supervisory control to achieve enhanced integration, moving from compliance to commitment (Clarke \& Newman, 62).

The interpretation offered by Clarke and Newman has two interesting components. First, it emphasises that the various extra-organisational attachments uphold by welfare professionals should be displaced in a twofold movement: the establishment of organisationally shared values, which should then be monitored more rigorously in terms of levels of performance -'measuring what really matters'. One may thus say that the strategy of deparadoxification is one of promoting the locally adaptable managerialism as universal. Or, putting it slightly different, dissolving those employee-attachments that transcend the specific organisational sites of employment (such as occupational values and collegiality), the new managerialism is universal in terms of its uniform objective of strengthening the local, corporate culture of all welfare organisations.

Second, Clarke and Newman points to another key deparadoxification strategy of NPM which consists in reformulating the division line and hierarchy between managers and employees by means of concepts that signals integration and togetherness: shared values, organisational culture, mutual interests, mutual commitment, and so on. The traditional image of an opposition between managers who instruct, demand, and sanction employees 'from above' is to be replaced by alliances, value consensus, and a shared outlook. To be sure, this strategy of downplaying and reconfiguring opposing interest between managers and their subordinates has for long been a strategic component in the 'soft' HRM and culture management which appeared around the late 1970s and onwards. Karen Legge thus critically observed that concepts of 'mutuality', 'interdependence' and moving 'from compliance to commitment' may serve a strategy of obfuscating fundamentally irreconcilable interests and potential conflicts between employer and employees (Legge, 2005). In the case of reforming welfare provision, NPM there strategy for overriding conflict lines between managers and employees has been one of creating a new distinction between 'core' and 'periphery'. This distinction makes it possible to speak of concentrating on 'core services' and that which can be contracted out, delegated to partners, or even left for revitalised communities and voluntary agencies. The idea of a pluralization of welfare provision by establishing a new kind of 'welfare mix' (Ascoli \& Ranci, 2002) or 'third sector 
involvement' (Anheier \& Seibel, 1990) designates strategies for establishing more networklike forms of services arrangements, in which the special qualities of the different agencies involved may 'blend', inspire and challenge tired out certainties of conventional welfare provision. The problem that these new network arrangements create new tensions and challenges in as far as multiple and sometimes incompatible professional logics become interlinked in networks comprising different professional and voluntary agencies has only begun being studied (Villadsen, 2008b).

The final paradox which is addressed and reformulated by NMP concerns the status of governance relations between central authorities and local welfare institutions. The degree of centralised control and monitoring of local services providers has, of course, been a longstanding issue in debates on public management. Arguments have revolved around the perceived tension between the governmental objective of ensuring equal standards, disciplining costs, and guaranteeing the observance of the national social law, on the one hand, and the need to grant local institutions room for manoeuvre allowing them to adjust services to local needs, invent new practices, and develop particular values. The classic paradox was, then, how central authorities could be at one and the same time a 'top-down' controller and a guarantor of local freedom. NPM offers a kind of a solution to this paradox by creating a space for central government as both maintaining responsibility for the local welfare provision by detailed supervision and performance audit and downplaying responsibility by emphasising that responsibility for concrete services delivery is a local matter. In this way, central government can adopt a double role in relation to welfare provision (Clarke and Newman, 1995: 81). On the one side, it claims to represent public interest by carrying out performance evaluations (or, perhaps rather, asking local services to carry them out), by disseminating information on how to manage, and by authorising particular quality standards and budgetary restraints. On the other side, central government wishes to delegate responsibility, grant organisations 'freedom to manage', and it requests 'local initiative to accommodate local conditions'.

The trick of de-paradoxification, it has been argued, is to make local welfare organisations accountable to central governments in a more indirect manner (Thygesen \& Andersen, 2004). The apparent withdrawal of centralised control of local services purported by NPM seems to be accompanied by a proliferation of new and mundane managerial technologies. These technologies render welfare organisations responsible and accountable to central authorities by making local organisations audit themselves (an audit which may be offered to the local services as a helping tool, the use of which might nevertheless be obligatory). More studies could be done to explore how specific managerial technologies are promulgated as tools to overcome the alleged division lines and paradoxes in public management (some fruitful advancements were made with respect to technologies of accountancy by Peter Miller (and his co-authors), although he did not address the problematic of governance through the concept of paradox (Kurunmäki \& Miller, 2006; Miller and Rose, 2009).

An alternative approach for overcoming problems, contradictions and paradoxes in welfare provision which we will mention only briefly is the Governance approach (Rhodes, 1996; Kooiman, 2003). Advocates for this approach to reform welfare provision typically oppose themselves against the key tenets of NPM. The point of departure of governance theorists is a decentring of the state, which in their view is traversed by a plethora of competing 
interests, pressure groups and networks of public, private and voluntary organisations. They describe (some of them commemoratively) how reforms of welfare states from the 1980s onwards have effected a shift from government through hierarchic bureaucracy to a network-based governance that involves market agents, quase-markets and voluntary agencies in the delivery of public services. From this observation, Governance scholars posits a greater complexity and fragmentation of state power, where central authorities increasingly depend upon other, non-state actors to implement policies and secure the delivery of what is still considered public services (Bevir, 2010: 436)

In terms of welfare provision, a key problem for these scholars is how to establish democratic bottom-up processes in which citizens and user groups participate in the definition of welfare services, particularly through different types of user boards. That paradoxes and contradictions in welfare services may be dissolved if services are turned more responsive to citizens' views is a general assumption for governance scholars. This assumption seems to rest on a conception of clients and users as rational agents who are self-conscious of their individual interests and preferences. In this way, the governance approach typically relocates both causes and solutions to paradoxes of welfare outside the institutions or in 'governance networks'. Establishing user-involvement in welfare services demands, however, that the users get a voice; that they views are somehow represented and channelled into welfare institutions. In this context, a new paradox emerge in the shape of a social services user who are at one and the same time in need of guidance from welfare professionals and a self-transparent knower of his own interests and needs. For this reason, perhaps, governance scholars pay particular attention to studying and discussing how the 'voice' of the services user can be heard devoid of external powers and other people's influences. Their general approach is that conflicts of interests are to be resolved by local and perhaps innovative forms of consensus-making in which solutions to particular problems are produced, as far as possible by the effected individuals themselves. In this context, I shall merely mention one key shortcoming of this framework for reforming welfare services and institutions. Focussing predominantly on user involvement, interorganisational networks, and consensus making processes the governance approach leaves little room for recognising paradoxes as an inherent property of welfare services.

\section{Conclusion}

This chapter has attempted to demonstrate the analytical force of applying a governmentality perspective supplemented with Luhmann's concept of paradox to the understanding of modern welfare provision. In particular, the analytical framework is well-suited to explore the inherent paradoxes of regulating welfare services, which we designated 'governmental paradoxes'. These paradoxes are to be found both at the level of professionals' interactions with citizens, at the level of management of welfare organisations, and on the level the governance relations between central authorities and local services units. In welfare provision, the paradoxes of universality, truth, and power were suggested as pervasive and enduring challenges to be tackled by professionals and programs for the organisation of services arrangements. A greater attention to these paradoxes as conditioning the spaces of action in welfare provision would, it is suggested, generate a better sense of what is at stake in current controversies and on-going developments. 
It was further argued that the major reform initiatives for re-invigorating welfare services, NPM and governance theory, do not addresses governmental paradoxes in a satisfactory manner. Whether the approach to welfare paradoxes is one of more user-involvement in the definition of services or one of the employment technical tools for carrying out managerial strategies, paradoxes are thought of as something to be done away with. It is thus telling that what I have termed governmental paradoxes would normally be described as 'dilemmas', 'tough choices', 'contradictions', 'ambiguous normative pressures' etc. The two dominant approaches within public management research do not conceive of paradoxes as a fundamental condition of management. Despite the many differences in their views of welfare management, they both adhere to a problem-and-solution scheme that understands the paradox as a temporary obstacle and something which can be surmounted.

However, in the approach adopted here borrowing upon the governmentality-framework and some basic suggestions for the study of paradoxes in Luhmann, paradoxes are not dissolvable. They are logical impossibilities which will continue to exist and manifest themselves as long as there is such a thing as modern welfare provision. Further studies are needed to understand processes of de-paradoxification which can similarly be expected to be a persisting activity that takes many shapes across different avenues of welfare provision. I suggest that we be ready to acknowledge that de-paradoxification work may be certainly be burdensome in some instances, but that it might produce new possibilities and feed positively into welfare services in others. One positive effect of de-paradoxification could for instance consist in the reformulation of lines of confrontations between groups or contradictions between values which appear as fixed and 'stifled'. This is what I take to be implied in the suggestion to 'unleash the paradoxes' in public management (Majgaard, 2009). This view also has implications for practitioners. It means that we should not aim to dissolve the paradoxes or 'take sides' with respect to their irreconcilable demands; we should rather understand how paradoxes, as well as being problematic, are also always productive, in as far as they generate debate, provoke contestations of existing arrangements, and call for new solutions.

\section{References}

Andersen, N.Å. (2008) Partnerships: Machines of possibility, Bristol: The Policy Press.

Andersen, N. A. (2009) Power at Play: The Relationships between Play, Work and Governance, Houndmills: Macmillan.

Anheier, H. K. \& Seibel, W. eds. (1990) The Third Sector: Comparative Studies of Non-ProfitOrganisations, Berlin: De Gruyter.

Ascilo, U. \& Ranci, C. eds. (2002) Dilemmas of the Welfare Mix: The New Structure of Welfare in an Era of Privatisation, New York: Kluwer.

Barry, A., Osborne, T. and Rose, N. (eds.) (1996) Foucault and Political Reason: Liberalism, Neoliberalism and Rationalities of Government, UCL Press: London.

Bevir, M. (2010) 'Rethinking Governmentality: Towards genealogies of governance', European Journal of Social Theory, 13: 423-442.

Borch, C. (2005) "Systemic Power: Luhmann, Foucault, and the Analytics of Power", Acta Sociologica 48(2): 155-167.

Botelho, R. (2002) Beyond Advice 2: Developing Motivational Skills. www.motivatehealthyhabits.com. 
Bozeman, B. (1993) Public Management: The state of art, San Francisco: Jossey Bass Publishers.

Clarke, J and Newman, J. (1997) The managerial state: power, politics and ideology in the remaking of social welfare, London: Sage

Clausen, S.M. (2005) Hash-samtalen. Om uge og hashrygning, København: Komiteen for Sundhedsoplysning.

Cruikshank, B. (1999) The Will to Empower: Democratic citizens and other subjects, Ithaca: Cornell University Press.

Dalum, P., Sonne, T.S. and Davidsen, M. (2000) At tale om forandring. En bog om sundhedsadfard og motiverende samtale-teknik. København: Tobaksskaderådet.

Dean, M. (1999) Governmentality: Power and Rule in Modern Society. London: Sage Publications.

Du Gay, P. (2000) In Praise of Bureaucracy: Weber, organisation, ethics, London: Sage.

Ferlie, E., L. Ashburner, L. Fitzgerald and A. Pettigrew (1996) The New Public Management in Action, Oxford: Oxford University Press.

Foucault, M. (2008) The Birth of Biopolitics: Lectures at the College De France, 1978-1979, London: Palgrave Macmillan.

Foucault M. (1995) Discipline \& Punish: The Birth of the Prison, New York: Vintage Books.

Foucault M. (1982) 'The Subject and Power', Critical Inquiry 8(4): 777-795.

Foucault M. (1980a) 'Truth and Power', in: M. Foucault (1980) Power/knowledge - selected interviews $\mathcal{E}$ other writings by Michel Foucault. New York: Pantheon Books.

Foucault, M. (1970) The Order of Things: An Archaeology of the Human Sciences, London: Tavistock

Foucault, M. (1994) 'Omnes et Singulatim: Toward a Critique of Political Reason', in M. Foucault: Power: Essential Works of Foucault 1954-1984, pp. 298-325. New York: The New Press.

Foucault, M. (2007 [2004]) Security, Territory, Population, New York: Palgrave Macmillan.

Gordon, C. (1991) 'Governmental rationality: an introduction', in G. Burchell, C. Gordon and P. Miller (eds.) The Foucault Effect: Studies in Governmentality. London: Harvester/Wheatsheaf, pp. 1-51.

Hindess, B. (1993) 'Liberalism, Socialism and Democracy, Variations on a Governmental Theme', Economy and Society 22(3): 300-313

Højlund, H. (2009): 'Hybrid Inclusion: The New Consumerism of Danish Welfare Services', Journal of European Social Policy, 19(5): 421-431

Karlsen, M.P. and Villadsen, K. (2008) 'Who should do the talking: The proliferation of dialogue as governmental technology', Culture \& Organization, 14(4): 345-363.

Kneer, G. and Nassehi, A. (2000) Niklas Luhmanns Theorie sozialer Systeme: Eine Einführung, München: UTB.

Kooiman, J. (2003) Governing as Governance, London: Sage.

Kurunmäki, L. and Miller, P. (2006) 'Modernising Government: The Calculating Self, Hybridisation and Performance Measurement', Financial Accountability $\mathcal{E}$ Management, 22(1): 87-106.

Lane, J. E. (2000) New Public Management, London: Routledge.

Larsen, L.T. (2003) 'Biopolitical Technologies of Community in Danish Health Promotion', Conference paper at: Vital Politics: Health, Medicine, and Bioeconomics into the Twenty First Century, London: London School of Economics. 
Legge, K. (2005) Human Resource Management: Rhetorics and realities, London: Palgrave Macmillan.

Luhmann, N. (1991) 'Stenographie und Euryastalik', pp. 58-82 in: H. U. Gumbrect \& K. L. Pfeiffer (eds.) Paradoxien, Dissonanzen, Zammenbrüche. Situationen offner Epistemologie, Frankurt: Suhrkamp.

Mabeck, C. E. et al. (1999) Den motiverende samtale, Viborg: Budolfi tryk.

Mabeck, C. E. (2003) 'Fedmeepidemiens uskyldige ofre', Månedsskrift for praktisk lægegerning. September: 1171-1175.

Majgaard, K. (2009): 'Slip paradokserne løs! Laboratorier for ny offentlig styring', Økonomistyring \& Informatik, 24(3): 261-302.

Meier, K.J. (1997) 'Bureaucracy and democracy: The case for more bureaucracy and less democracy', Public Administration Review, 57(3): 193-9

Miller, P. and Rose, N. (2008) Governing the Present: Administering Economic, Social and Personal Life, London: Polity Press.

Miller, W.R. and Rollnick, S. (1991) Motivational Interviewing: Preparing People for Change, New York: Guilford Press.

Mik-Meyer, N. (2006) 'Identities and Organizations: Evaluating the Personality Traits of Clients in two Danish Rehabilitation Organizations', Critical Social Studies, 8(1): 3248.

Mundt, K et al. (2003) Alkohol - forebyggelse på sygehus. Fakta metoder og anbefalinger, København: Klinisk Enhed for Sygdomsforebyggelse.

Nielsen, A. S. (1998) 'Få din patient til at ændre livsstil: Om motivationsskabende samtaleteknikker', Månedsskrift for praktisk lægegerning, 6: 735-743.

Osborne, S. (2007) 'The New Public Governance?', Public Management Review, 8(3): 377-387.

Philp, M. (1979) 'Notes on the Form of Knowledge in Social Work', The Sociological Review, 27(1): 83-111.

Pollitt, C. (1993) Managerialism and the public services: cuts or cultural change in the 1990s?, Oxford: Blackwell Business.

Pottage, A. (1998) 'Power as an Art of Contingency: Luhmann, Deleuze, Foucault', Economy and Society, 27(1): 1-27.

Rhodes, R. A. W. (1996) 'The New Governance: Governing without Government', Political Studies, 44: 652-667.

Rose, N. and Miller, P. (1992) 'Political Power beyond the State: Problematics of Government', The British Journal of Sociology, 43(2): 173-205.

Rose, N. (1993) 'Government, Authority and Expertise in Advanced Liberalism', Economy and Society 22(3): 283-99.

Rose, N. (1999) Powers of Freedom: Reframing Political Thought, Cambridge: Cambridge University Press.

Stacey, R. (2003) 'Learning as an Activity of Interdependent People', The Learning Organisation, 10(6): 325-331.

Sørensen, T. B. (2001) Metodebog for projekter: Aktivering og forrevalidering, Sociologisk Analyse, Risskov: Forlaget Gestus.

Thygesen, N.T. \& Andersen, N.A. (2004) 'Styringsteknologier $i$ den selvudsatte organisation', GRUS, 73(25): 8-29 
Thygesen, N.T. \& Andersen, N. Å. (2007) 'The Polyphonic Effects of Technological Changes in Public Sector Organizations: A Systems Theoretical Approach', Ephemera: Theory and politics in organization, 7(2): 326-345.

Valverde, M. (1996) "Despotism" and Ethical Liberal Governance', Economy and Society 25(3): 357-372.

Villadsen, K. (2004) Det sociale arbejdes genealogi: Kampen for at gøre fattige og udstødte til frie mennesker, København: Hans Reitzels Forlag.

Villadsen, K. (2007) 'The Emergence of "Neo-Philanthropy": A New Discursive Space in Welfare Policy?', Acta Sociologica 3(50): 309-323.

Villadsen, K. (2008a) "Doing without the State and Civil Society as Universals: 'Dispositifs' of care across the classic sector divide", Journal of Civil Society, 4(3): 171-191.

Villadsen, K. (2008b) "'Polyphonic' Welfare: Luhmann's systems theory applied to modern social work", International Journal of Social Welfare, 1(17): 65-73.

Villadsen, K. (2009) "The 'Human Touch': Voluntary organizations as rescuers of social policy?", Public Management Review, 2(11): 217-234.

Villadsen, K. (2011a) "Ambiguous Citizenship: Modern and postmodern welfare at the margins", Distinktion: Scandinavian Journal of Social Theory, 12(3): 309-329

Villadsen, K. (2011b) "Modern Welfare and 'Good Old' Philanthropy: A forgotten or a troubling trajectory?", Public Management Review, 13(8): 1057-1075. 


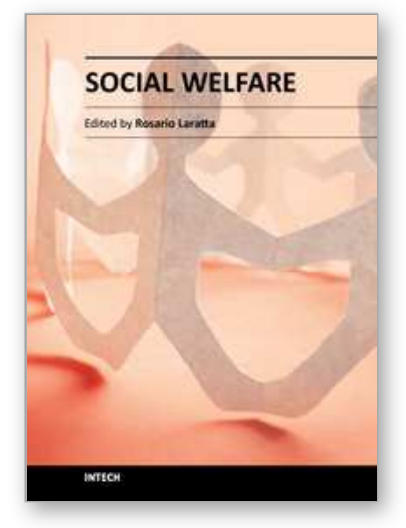

\author{
Social Welfare \\ Edited by Dr. Rosario Laratta
}

ISBN 978-953-51-0208-3

Hard cover, 216 pages

Publisher InTech

Published online 07, March, 2012

Published in print edition March, 2012

"Social Welfare" offers, for the first time, a wide-ranging, internationally-focused selection of cutting-edge work from leading academics. Its interdisciplinary approach and comparative perspective promote examination of the most pressing social welfare issues of the day. The book aims to clarify some of the ambiguity around the term, discuss the pros and cons of privatization, present a range of social welfare paradoxes and innovations, and establish a clear set of economic frameworks with which to understand the conditions under which the change in social welfare can be obtained.

\title{
How to reference
}

In order to correctly reference this scholarly work, feel free to copy and paste the following:

Kaspar Villadsen (2012). Paradoxes of Welfare: Universality, Truth, and Power in Modern Welfare Provision, Social Welfare, Dr. Rosario Laratta (Ed.), ISBN: 978-953-51-0208-3, InTech, Available from: http://www.intechopen.com/books/social-welfare/paradoxes-in-welfare-provision

\section{INTECH}

open science | open minds

\section{InTech Europe}

University Campus STeP Ri

Slavka Krautzeka 83/A

51000 Rijeka, Croatia

Phone: +385 (51) 770447

Fax: +385 (51) 686166

www.intechopen.com

\section{InTech China}

Unit 405, Office Block, Hotel Equatorial Shanghai

No.65, Yan An Road (West), Shanghai, 200040, China 中国上海市延安西路65号上海国际贵都大饭店办公楼405单元

Phone: +86-21-62489820

Fax: $+86-21-62489821$ 
(C) 2012 The Author(s). Licensee IntechOpen. This is an open access article distributed under the terms of the Creative Commons Attribution 3.0 License, which permits unrestricted use, distribution, and reproduction in any medium, provided the original work is properly cited. 